Original Article

\title{
Outcome of Patients Operated for Depressed Skull Fracture (DSF) with Dural Tear
}

\author{
Muhammad Tariq ${ }^{1}$, Mushtaq Ahmad Mian², Faiqa Filza', Shahid Ayub ${ }^{3}$ \\ Sohail Daud Khan ${ }^{1}$, Khial Jalal ${ }^{1}$ \\ ${ }^{1}$ Northwest General Hospital \& Research, ${ }^{2}$ Rehman Medical Institute, Hayatabad \\ ${ }^{3}$ Hayatabad Medical Complex, Peshawar - Pakistan
}

\section{ABSTRACT}

Objective: The objective of this study was to determine the outcome of patients operated for depressed skull fracture with a dural tear.

Material and Methods: A descriptive case series $(n=155)$ was carried out in the Department of Neurosurgery, Hayatabad Medical Complex Peshawar for six months.

Results: The mean arrival GCS was $10.64 \pm 2.33$. About $21.9 \%(n=32)$ patients presented with a GCS of $\leq 8$, while the remaining $78.1 \%(n=123)$ presented with a GCS of $\geq 8$. About $8.4 \%(n=13)$ patients died due to the complications of the brain injury. The most common postoperative complication was found to be progressive neurologic deficit (PND) occurred in 21 (13.5\%) patients. Penetrating injury to the head was also associated with unfavorable outcomes after surgery $(p=0.046)$, which shows that penetrating injury is associated with increased brain damage and hence consequently poor outcomes.

Conclusions: The neurologic status as denoted by the Glasgow coma scale is one of the most important factors which predicts the outcome. Surgical management of depressed skull fractures with dural tear has favorable outcomes in about two-thirds of patients. The remaining one-third patient remains in the severely disabled group. Every effort should be made to reduce the occurrence of complications as they are directly related to postoperative functional outcomes.

Keywords: Depressed Skull Fracture (DSF), Dural Tear, Surgical Outcome.

\section{Corresponding Author: Muhammad Tariq \\ Northwest General Hospital \& Research, Peshawar, Pakistan \\ Email: tariqbarki2@gmail.com}

Date of Submission: 16-04-2021

Date of Revision: 01-04-2021

Date of Online Publishing: 13-06-2021

Date of Print: 30-06-2021

DOI: $10.36552 /$ pjns.v25i2.523

\section{INTRODUCTION}

Head trauma has become the fourth-largest cause of death and disability worldwide over the previous two decades. The social and economic impact of traumatic brain injuries are immense while the health-related impact on individual and families are drastic. ${ }^{1}$ Head injuries are frequently associated with fractures of the skull as a result of 
direct impact on the head in closed head injuries while the open type of head injuries such as penetrating injuries of the skull does obviously are always associated with fractures of the skull. There are two major types of skull fractures, i.e., linear skull fracture and ii) depressed skull fracture. Other types of skull fractures are growing skull fracture, basilar skull fractures, diastatic skull fractures and elevated skull fracture, which in reality are the subtypes of the first two types. Studies have shown that the occurrence of skull fracture is an independent predictor of the underlying severity of injury and the probable outcome associated with such injuries. ${ }^{2-3}$

Depressed skull fractures are associated with about $12 \%$ to $20 \%$ of severe head injuries. Involvement of dural venous sinuses and tears in the dura mater caused due to the traumatic injury to the skull determines whether intervention is required or not. It also indicates complications. Near half (48\%) the number of skull fractures, have associated dural tears. They lead to EDH or extradural hematomas, cerebral contusions, or parenchymal bleeds. ${ }^{4-5}$ A study by Mushtaq et al ${ }^{4}$ showed the frequencies of various types of depressed skull fracture. Dural tears were seen in $47.9 \%$ of these cases. The outcome was analyzed according to the Glasgow outcome scale (GOS) where groups of favorable and unfavorable outcomes were made. Recovery was good in $72.9 \%$ of patients (GOS 5 ) while the remaining (27.1\%) were grouped as unfavorable outcomes. ${ }^{4-}$ 5 This study will analyze that depressed skull fractures turn out in terms of GOS, the incidence of focal deficits, wound infection, meningitis, seizures, and development of CSF leaks after surgery for depressed fracture with the presence of a dural tear.

The skull protects the brain. There is a cushion of cerebrospinal fluid (CSF) surrounding the brain, protecting it inside the skull. The scalp fascia and muscles also impart a highly effective cushioning to the skull. Tests on the cadaveric skull show a 10 times difference in force required to fracture a skull with a scalp than the one without it. ${ }^{6}$ However, the meningeal attachments inside the skull do not allow free movement of the brain. Shearing external forces of impact get transferred readily to the brain. The skull vault varies in thickness. The middle cranial fossa particularly, owing to thin bones and various foramina is the weakest among the skull bones. Skull fractures can be linear or depressed. Linear fractures occur in the vault or skull base. ${ }^{7}$ These fractures of the vault can be open and contaminated or closed and clean. The commonest skull fracture to occur is the simple linear fracture that occurs more commonly in children below 5 years of age. Of all the skull fractures, Temporal bone fractures occur in $15-48 \%$. Basilar skull fractures occur in $19-$ $21 \%$. Depressed fractures are generally open fractures (75-90\%). In mild head injuries, plain Xrays show skull fractures in $5 \%$ of cases. Indicating the need for a CT scan. Skull X-rays have not been abandoned, as suggested by many studies, owing to their support in detecting non-accidental trauma. ${ }^{8}$

Mogbo et al in a retrospective analysis suggested the use of routinely performing CT scans of children (less than 2 years) with skull fractures. ${ }^{9}$ A total of 87 consecutive children with skull fractures were included that had skull fractures on X-rays; 67 children did not have neurological deficits. 35 (52\%) of these were not CT scanned CT scanning, and none of them had any delayed findings. Dacey et $\mathrm{al}^{10}$ assessed the risks of neurosurgical complications after minor head injury and drew some conclusions as follows: The presenting GCS score between 13 15 does not determine if the injury is trivial or minor. $3 \%$ of patients with normal initial GCS underwent surgery. An abnormal X-ray skull increases the probability of neurosurgical intervention by 20 fold. It is rare to have a neurosurgical complication in a patient with a normal GCS of 15 and a normal X-Ray skull. In suspected cases of fractures of the skull and intracranial injury, a CT scan is the investigation of 
choice. The bone window of $1-1.5 \mathrm{~mm}$ thickness help in the assessment of cerebral injuries. ${ }^{11-12}$ Freund et al had a comparative analysis of the MRI and CT scan images in 30 skull fractures. Although MRI and CT both showed orbital floor fractures, equally, CT was superior in highlighting small and associated fractures. ${ }^{13}$ However, MRI takes the details in soft-tissue herniation and entrapments in a better way..$^{13}$ Lata et al $^{14}$ found that a real-time ultrasound of the orbit for cases of trauma was adequate enough in a display of the anatomy of the orbit. It depicted important features. It showed that ultrasound can also play a role in post-traumatic imaging of the orbit when CT scan was not possible. ${ }^{14-15}$

Decarie and Mercier studied the role of ultrasound in diastatic skull fractures and dural injury, finding it to be a promising tool. ${ }^{16}$ Infants with fractures of the skull are essentially admitted for observation. Their neurological status can be unpredictable. Adults with simple linear fractures, however, are discharged home, if they are asymptomatic and without neurological deficits. ${ }^{14}$ The role of surgery is limited in fractures of the skull. Surgery is often required in for open and depressed fractures in infants and children. If the depression of bone is more than $5 \mathrm{~mm}$ below the inner table, most surgeons favor elevation. ${ }^{16}$ In a retrospective study by Bonfield et al $^{17}$ the majority of pediatric trauma of skulls required conservative care. The only indication for surgery was the repair of the skull fracture. Surgical intervention was done in skull injuries in motor vehicle accidents or fast-moving objects hitting the head. Patients with traumatic brain injury had a higher incidence of fractures of 2 or 3 bones of the skull. If the frontal bone was fractured, the need for surgery was higher. Complications were related to the trauma and rarely associated with the surgery. Surgery did not cause worsening of neurological status. ${ }^{17}$

Fragments of the bone are elevated before inspection of the dura can be done. The dural tear is repaired. Epidural hematomas can develop and homeostasis is mandatory and should be meticulously done to avoid this post-operative complication. Bony fragments used to soak in the solution of isotonic sodium chloride followed by reassembling. Wiring can be done to fuse two or more fragments of larger size. The use of titanium mesh is not uncommon to cover the defect. The use of Methy Methacrylate is avoided and absorbable bone plates and screws are used in children. A stable, neurologically intact patient must be observed. Skin debridement is considered for neurologically stable patients with open depressed fracture over a patent venous sinus, without doing an elevation of the fracture. In an intact patient with thrombosed sinus, ligation of the sinus is considered harmless. ${ }^{18}$ Long-term follow-ups are not required in patients who are intact on presentation and have no complications following linear skull fractures. Infants need close monitoring in such fractures where dural tears occur and fractures tend to expand. Patients with contaminated open depressed skull fractures who are surgically treated should be followed up with a few repeated CT scans in 2 to 3 months, to observe for the formation of an abscess. The known complications of skull fractures are seizures and infections. These dictate the frequency and duration of follow-ups. When fractures are missed or not recognized, the complications can be worse than treating them. ${ }^{19}$ Skull fractures are often associated (15\%) with a concomitant cervical spine injury and should be kept in mind in all head trauma cases. ${ }^{20-21}$ Elevation of depressed fractures and the use of antibiotics face controversies. Antibiotics are reserved for open fractures with obvious contamination. The cosmetic aspects of head injury and choice of the treatment by surgeon dictate the elevation of bony fractures. ${ }^{22}$ Incorporation of the resorbable bone plates cross-links with Bone matrix protein2 (BMP-2) which follows the healing of the fracture. $^{23}$ 


\section{MATERIAL \& METHODS}

The objective of this study was to determine the outcome of patients operated for depressed skull fracture with dural tear.

\section{Study Design \& Setting}

A descriptive case series was conducted for six months, at the Department of Neurosurgery, Hayatabad Medical Complex, Peshawar. The patients were admitted through the outpatient department or emergency/accident ward.

\section{Sample Size \& Technique}

The calculated sample the size was 155 patients by using $72.9 \%$ favorable outcome for the depressed skull fractures, taking $95 \%$ confidence level and $7 \%$ margin of error with WHO software. A non-probability consecutive sampling method was considered.

\section{Inclusion Criteria}

All head injury patients, both male and female of 18 years to 65 years presenting with a diagnosis of depressed skull fracture with operative findings of a dural tear.

\section{Exclusion Criteria}

Simple and closed depressed fracture patients who either do not require surgery or has no dural tear by criteria outlined were excluded. Cases of linear skull fractures and penetrating head injury patients were also excluded.

\section{Data Collection}

The data was collected with a designed proforma. The included information was age, gender, admission number, mode of admission, admission GCS, location fracture, and operative findings of the dural tear.

\section{Diagnosis of Depressed Skull Fracture}

Diagnosis of DSF was made on clinical examination and radiological findings. The presence or absence of dural tear was confirmed on open surgical exploration. An experienced Neurosurgeon decided for the operative or conservative treatments. Patients who needed surgery were operated under general anesthesia by an expert Neurosurgeon.

\section{Follow-up}

Patient was followed post-operatively till discharge from the hospital. The patients were assessed by a Neurosurgeon for the outcome (GOS) at discharge and the presence of any unfavorable factors like wound infection, CSF leak, meningitis, focal deficits, and the occurrence of epileptic fits were noted. Observation and examination were also performed by a trainee medical officer and data were recorded on a predesigned proforma. In order to avoid the bias and to control the cofounders, the selection criteria was followed. Operative findings were recorded mentioning the presence or absence of dural tear. All investigations were performed inside the hospital.

\section{Data Analysis}

SPSS version 25 was used to enter and analyze the descriptive and quantitative variables including frequencies. The variable outcome was stratified for age, gender, dural tear, and GCS scores (initial). Chi-square test was applied to the post-stratified data and its significance. The pvalue of less than 0.050 was considered significant.

\section{RESULTS}

\section{Gender \& Age Distribution}

In a total of 155 patients, there were 106 (68.4\%) male and 49 (31.6\%) female patients. Mean overall age was 24.92 years \pm 6.47 SD.

Pak. J. of Neurol. Surg. -2021 - 25 (2): 126-133. 


\section{Distribution of Fractures \& Injuries}

There were 66 (42.6\%) cases of simple depressed fracture and 89 (57.4\%) cases of compound depressed fracture. In 59 (38.1\%) cases, the injury was caused by road traffic accident (RTA), falls in 45 (29.0\%) cases, falling object in 16 (10.3\%) cases, assault in $18(11.6 \%)$, penetrating object in $13(8.4 \%)$ cases, and crush injury in $4(2.6 \%)$ of cases.

\section{Information in GCS Scores}

The mean arrival GCS was $10.64 \pm 2.33$. About $21.9 \%(n=32)$ patients presented with a GCS of $\leq 8$ while the remaining $78.1 \%(\mathrm{n}=123)$ presented with a GCS of $\geq 8$. Mean Glasgow comma score (GOS) at the end of follow-up period was $3.79 \pm 1.25 \mathrm{SD}$. At the end of the follow-up period, there were $32.9 \%(n=51)$ cases with an unfavourable outcome according to GOS while 104 (67.1\%) patients achieved favourable outcome.

\section{Complications}

In this study, about $8.4 \%(n=13)$ of patients died due to the complications of the brain injury. The most common postoperative complication was found to be progressive neurologic deficit (PND) which occurred in 21 (13.5\%) patients. This was followed by the occurrence of postoperative CSF leak in 14 (9.0\%) cases. Wound infection occurred in $12(7.7 \%)$ patients while meningitis was observed in 9 (5.8\%) patients. The data were stratified for outcome groups as well as their association with the occurrence of complications (Tables 1 - 2). The overall Glasgow outcome score distribution is represented in Table $\mathbf{3}$.

\section{Statistical Analysis}

A Chi-square test was run for determining the association between gender and outcome groups and it was observed that there was no statistically significant association between gender and outcome after surgery ( $p=0.057)$. There was no association between fracture type and outcome $(p=0.96)$. It was observed that injury due to road traffic accidents (RTA) was associated with unfavorable outcomes ( $p=0.012$ ). Penetrating injury to the head was also associated with unfavorable outcomes after surgery $(p=0.046)$ which shows that penetrating injury is associated with increased brain damage and hence consequently poor outcomes.

Table 1: Variables stratified for outcome groups.

\begin{tabular}{|lcc} 
Variable & $\begin{array}{c}\text { Favourable } \\
\text { Outcome } \\
(\mathbf{n = 9 9 )}\end{array}$ & $\begin{array}{c}\text { Unfavourable } \\
\text { Outcome } \\
(\mathbf{n}=\mathbf{5 6})\end{array}$ \\
Age & $25.19 \pm 6.5$ & $24.43 \pm 6.45$ \\
Arrival GCS & $11.55 \pm 1.78$ & $9.04 \pm 2.34$ \\
GOS 1 month & $4.55 \pm 0.5$ & $2.45 \pm 1.03$ \\
\hline
\end{tabular}

Table 2: Postoperative complications for the two outcome groups.

\begin{tabular}{lcccc} 
Complication & $\begin{array}{c}\text { Favourable } \\
\text { Outcome } \\
\text { (n=99) }\end{array}$ & $\begin{array}{c}\text { Unfavourable } \\
\text { Outcome } \\
\text { (n=56) }\end{array}$ \\
$\begin{array}{l}\text { Frequency Percent } \\
\text { Progressive } \\
\text { neurological }\end{array}$ & - & - & 21 & $37.5 \%$ \\
$\begin{array}{l}\text { Deterioration } \\
\text { Meningitis }\end{array}$ & 1 & $1.0 \%$ & 8 & $14.3 \%$ \\
$\begin{array}{l}\text { CSF leak } \\
\begin{array}{l}\text { Wound } \\
\text { infection }\end{array}\end{array}$ & 3 & $3.0 \%$ & 11 & $19.6 \%$ \\
\hline
\end{tabular}

Table 3: GOS distribution at the end of the follow-up.

\begin{tabular}{ccc} 
Glasgow Outcome Score & Frequency & Percent \\
1 & 13 & 8.4 \\
2 & 12 & 7.7 \\
3 & 26 & 16.8 \\
4 & 48 & 31.0 \\
5 & 56 & 36.1 \\
\hline
\end{tabular}

On Chi-square analysis between the postoperative complications and outcome, it was observed that except for wound infection which 
was not associated with unfavorable outcome $(p=0.83)$, rest of the postoperative complications were strongly associated with unfavorable outcomes in terms of GOS ( $p<0.001)$.

\section{DISCUSSION}

Fractures of the skull bones commonly occur in head injury and is frequently associated with intracranial complications of the force of impact. It is estimated that a force above $400 \mathrm{Kg} / \mathrm{m}^{2} / \mathrm{sec}$ is required to break the skull bone. Depressed skull fracture in itself is the accurate indicator of the severity of the applied force. In cases where the severe intracranial injury occurs due to the overlying bone fracture, the outcome is primarily related to the intracranial or parenchymal component of the injury. ${ }^{24}$

This study included adult patients of depressed skull fracture with dural tear and analyzed their functional outcome in terms of Glasgow outcome score (GOS) at one month after surgery. In our study, the patient demographics were similar to most other studies showing this shows that younger individuals with a productive life are frequently affected by a head injury in which at least one-third of individuals present with a GCS of 8 or below. Rehman et $\mathrm{al}^{25}$ in a prospective study operated on 56 patients with a male to female ratio of $4.6: 1$ and a mean age of 21.7 years. In their series, the most common cause of injury was fall.

In majority of individuals, the depressed fractures are compound with an overlying scalp laceration. Such patients with a dural tear are at an increased risk of contracting meningeal or cerebral infective complications as well as a higher risk of seizures and focal deficits. In our study, more than half of the patients presented with a compound fracture while only $42 \%$ presented with a simple depressed fracture. These findings are similar to the studies of Rehman et $\mathrm{al}_{1}{ }^{26}$ Hossain et $\mathrm{al}^{27}$ and Ersahin et $\mathrm{al}_{1}{ }^{28}$ where most of the patients presented with a compound depressed fracture.

A positive correlation was found in our study, between presenting GCS and neurological and functional outcomes. Patients with a mean GCS of $9.04 \pm 2.34$ had a worse outcome compared to those with GCS of $11.55 \pm 1.79$ that had a favorable outcome. Ersahin et al. ${ }^{28}$ concurred with these findings. Many authors and studies have approved the efficacy of GCS as an initial assessment tool for final outcome and prognosis. ${ }^{24,29}$ In our patients, $65 \%$ patients had a favorable outcome in terms of GOS. $8.4 \%$ of patients died because of the consequences of brain trauma. Various authors have reported a mortality rate ranging from $1 \%$ to more than $6 \%$. Old literature suggests mortality reaching up to $30 \%$, which as reported has improved over time.

\section{CONCLUSION}

Depressed fracture is frequently encountered trauma in a neurosurgical care facility. The neurologic status as denoted by the Glasgow coma scale is one of the most significant factors in predicting outcome. Surgical management of depressed skull fractures with dural tear has favorable outcomes in about two-thirds of patients. The remaining one-third patient remains in the severely disabled group. Complications including mortality are high, however, considering the gravity of injury in a depressed skull fracture, such complications are predictable. Every effort should be made to reduce the occurrence of complications as they are directly related to postoperative functional outcomes.

\section{REFERENCES}

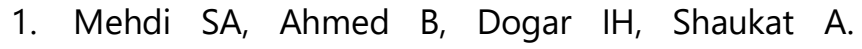
Depressed skull fracture; Interrelationship between CT evaluation \& its clinical findings. Prof Med J. 2010; 17 (4).

2. Ohaegbulam SC, Mezue WC, Ndubuisi CA, Erechukwu UA, Ani CO. Cranial computed tomography scan findings in head trauma patients

Pak. J. of Neurol. Surg. -2021 - 25 (2): 126-133. 
in Enugu, Nigeria. Surgical Neurology International, 2011; 2 .

3. Provenzale JM. Imaging of traumatic brain injury: a review of the recent medical literature. Am J Roentgenol. 2010; 194 (1): 16-9.

4. Mushtaq, Azam F, urRehman R, Khattak A, Alam W, Anayatullah. Surgical management and outcome of depressed skull fracture. Pak J Neurol Surg. 2010; 14 (1): 30-4.

5. Wang W-h, Lin J-m, Luo F, Hu L-s, Li J, Huang W. Early diagnosis and management of cerebral venous flow obstruction secondary to transsinus fracture after traumatic brain injury. J Clin Neurol. 2013; 9 (4): 259-68.

6. RC C. Head and spine injuries in youth sports. Clin Sports Med. 1995; 14 (3): 517-32.

7. Schaller $B$, Hosokawa $S$, Büttner $M$, lizuka $T$, Thorén $\mathrm{H}$. Occurrence, types and severity of associated injuries of paediatric patients with fractures of the frontal skull base. J Craniomaxillofac Surg. 2012; 40 (7): e218-e21.

8. Arrey EN, Kerr ML, Fletcher S, Cox Jr CS, Sandberg DI. Linear nondisplaced skull fractures in children: who should be observed or admitted? J Neurosurg Pediatr. 2015; 16 (6): 703-8.

9. Mogbo KI, Slovis TL, Canady Al, Allasio DJ, Arfken $\mathrm{CL}$. Appropriate imaging in children with skull fractures and suspicion of abuse. Radiology, 1998; 208 (2): 521-4.

10. Dacey Jr RG, Alves WM, Rimel RW, Winn HR, Jane JA. Neurosurgical complications after apparently minor head injury: assessment of risk in a series of 610 patients. J Neurosurg. 1986; 65 (2): 203-10.

11. Mukerji N, Cahill J, Paluzzi A, Holliman D, Dambatta S, Kane PJ. Emergency head CT scans: can neurosurgical registrars be relied upon to interpret them? Br J Neurosurg. 2009; 23 (2): 15861.

12. Mulroy MH, Loyd AM, Frush DP, Verla TG, Myers $B S$, Bass CR. Evaluation of pediatric skull fracture imaging techniques. Forensic Science International, 2012; 214 (1-3): 167-72.

13. Freund $M$, Hähnel $S$, Sartor $K$. The value of magnetic resonance imaging in the diagnosis of orbital floor fractures. Eur Radiol. 2002; 12 (5): 1127-33.

14. Lata A, Marcuzzi D, Forrest C. Comparison of realtime ultrasonography and coronal computed tomography in the diagnosis of orbital fractures. Canadian Assoc Radiol J. 1993; 44 (5): 371-6.

15. Bandak FA, Vander Vorst MJ, Stuhmiller LM, Mlakar PF, Chilton WE, Stuhmiller JH. An imagingbased computational and experimental study of skull fracture: finite element model development. Journal of Neurotrauma, 1995; 12 (4): 679-88.

16. Décarie JC, Mercier $C$. The role of ultrasonography in imaging of paediatric head trauma. Child Nerv Sys. 1999; 15 (11-12): 740-2.

17. Bonfield CM, Naran S, Adetayo OA, Pollack IF, Losee JE. Pediatric skull fractures: the need for surgical intervention, characteristics, complications, and outcomes: Clinical article. J Neurosurg Pediatr. 2014; 14 (2): 205-11.

18. Meltzer H, LoSasso B, Sobo EJ. Depressed occipital skull fracture with associated sagittal sinus occlusion. The Journal of Trauma, 2000; 49 (5): 981.

19. Sade B, Mohr G. Depressed skull fracture and epidural haematoma: an unusual post-operative complication of pin headrest in an adult. Actaneurochirurgica. 2005; 147 (1): 101-3.

20. Yokota H, Eguchi T, Nobayashi M, Nishioka T, Nishimura F, Nikaido $Y$. Persistent intracranial hypertension caused by superior sagittal sinus stenosis following depressed skull fracture. Case report and review of the literature. J Neurosurg. 2006; 104 (5): 849-52.

21. Vender JR, Bierbrauer K. Delayed intracranial hypertension and cerebellar tonsillar necrosis associated with a depressed occipital skull fracture compressing the superior sagittal sinus. Case report. J Neurosurg. 2005; 103 (5 Suppl): 458-61.

22. Huang Y, Simmons $C$, Kaigler D, Rice K, Mooney D. Bone regeneration in a rat cranial defect with delivery of $\mathrm{PEl}$-condensed plasmid DNA encoding for bone morphogenetic protein-4 (BMP-4). Gene Therapy, 2005; 12 (5): 418-26.

23. Shibuya TY, Wadhwa A, Nguyen KH, Panossian $A M$, Kim $S$, Wong $H$, et al. Linking of Bone Morphogenetic Protein-2 To Resorbable Fracture Plates for Enhancing Bone Healing. Laryngoscope, 2005; 115 (12): 2232-7.

24. Burns EC, Grool AM, Klassen TP, Correll R, Jarvis A, Joubert $G$, et al. Scalp hematoma characteristics associated with intracranial injury in pediatric minor head injury. Acad Emerg Med. 2016.

25. Rehman L, Ghani E, Hussain A, Shah A, Noman MA, 
KhaleeqUz Z. Infection in compound depressed fracture of the skull. Journal of the College of Physicians and Surgeons - Pakistan: JCPSP. 2007; 17 (3): 140-3.

26. Mathew MJ, Pruthi N, Savardekar AR, Tiwari S, Rao MB. Midline depressed skull fracture presenting with quadriplegia: A rare phenomenon. Surgical Neurology International, 2017; 8.

27. Hossain MZ, Mondle M, Hoque MM. Depressed skull fracture: outcome of surgical treatment. J Teacher Assoc. 2008; 21 (2): 140-6.

28. Ersahin $Y$, Mutluer S, Mirzai H, Palali I. Pediatric depressed skull fractures: analysis of 530 cases. Child Nerv Sys. 12 (6): 323-31.

29. Al-Haddad SA, Kirollos R. A 5-year study of the outcome of surgically treated depressed skull fractures. Annals of the Royal College of Surgeons of England. 2002; 84 (3): 196-200.

\section{Additional Information}

Disclosures: Authors report no conflict of interest.

Ethical Review Board Approval: The study was conformed to the ethical review board requirements.

Human Subjects: Consent was obtained by all patients/participants in this study.

Conflicts of Interest:

In compliance with the ICMJE uniform disclosure form, all authors declare the following:

Financial Relationships: All authors have declared that they have no financial relationships at present or within the previous three years with any organizations that might have an interest in the submitted work.

Other Relationships: All authors have declared that there are no other relationships or activities that could appear to have influenced the submitted work.

\section{AUTHORS CONTRIBUTIONS AFTER REVISION}

\begin{tabular}{|l|l|l|}
\hline Sr.\# & Author's Full Name and Affiliation & Intellectual Contribution to Paper in Terms of: \\
\hline 1. & $\begin{array}{l}\text { Muhammad Tariq, } \\
\text { Mushtaq Ahmad Mian Rehman }\end{array}$ & Study design and methodology. \\
\hline 2. & Mushtaq Ahmad Mian, Muhammad Tariq & Paper writing, referencing, and data calculations. \\
\hline 3. & Muhammad Tariq & Data collection and calculations. \\
\hline 4. & Shahid Ayub, Muhammad Tariq & Analysis of data and interpretation of results etc. \\
\hline 5. & Sohail Daud Khan, Faiqa Filza & Literature review and manuscript writing. \\
\hline 6. & Khial Jalal, Muhammad Tariq & Analysis of data and quality insurer. \\
\hline
\end{tabular}

